\title{
educação

\section{O Estágio Curricular Supervisionado como Lócus Central da Profissionalização do Ensino}

\author{
Samuel de Souza Neto \\ Universidade Estadual Paulista, Brasil \\ MARINA Cyrino \\ Fundação Hermínio Ometto, Brasil \\ CECILIA BORgES ${ }^{\text {III }}$ \\ Universidade de Montréal, Canadá
}

O presente artigo focaliza a formação inicial de professores e o movimento de profissionalização do ensino, tendo como objeto central de investigação o estágio curricular. Elencam-se duas questões de estudo para discussão: 1) Como a questão do estágio curricular supervisionado tem se manifestado na formação inicial de professores?; 2) As reformas propostas no âmbito da formação inicial docente a nível internacional e brasileiro, especificamente do estágio curricular, tomam a profissionalização como pressuposto? Inicialmente são apresentados aspectos conceituais sobre o processo de profissionalização do ensino. Em seguida, fazemos uma breve trajetória sobre como a formação docente foi compreendida e concebida no âmbito da prática. Posteriormente, exploramos alguns exemplos do Brasil, França e Canadá. Nas análises realizadas, observamos que, a partir do processo de profissionalização, a universidade e as instituições de ensino superior assumem a formação inicial de professores, tendo que se estruturar e se organizar para atender suas demandas específicas, assumindo elementos da proposta do modelo profissional de formação.

Palavras-chave: Atribuição causal; Motivação para a aprendizagem; Ensino Básico; Avaliação psicoeducacional

\section{IN T R O DUÇ Ã O ${ }^{1}$}

Historicamente, tanto no Brasil quanto no contexto internacional, a formação inicial docente passou por grandes mudanças paradigmáticas, priorizando aspectos ligados ao nível de ensino em que o professor deveria ser formado (início do século XIX até a primeira metade do século XX), até a concepção do que e/ou como ensinar (segunda metade do século XX) (Tardif, 2013; Villela, 2004). Assim, a formação inicial, por exemplo,

Este trabalho está vinculado ao Projeto CNPq-439325/2018-8/Universal - Por uma Pedagogia do Estágio Supervisionado: da proposta de formação de professores de educação física ao acolhimento e acompanhamento da prática de ensino na escola. 
passou de modelos voltados ao aprendizado das técnicas de ensino, conteúdos de ensino, para modelos que valorizavam o conhecimento sobre a aprendizagem dos alunos, como ensinar, oferecendo, assim, um saber científico ao professor (Gauthier, Martineau, Desbiens, Malo, \& Simard, 1998). Mais recentemente, há uma ênfase que valoriza o saber docente, a reflexão sobre a prática, a pesquisa no ensino, as competências na formação (Ghedin, 2009; Ghedin, Oliveira, \& Almeida, 2015).

No entanto, mesmo com as mudanças, por volta dos anos 80, o trabalho do professor passou a ser foco de questionamentos que o vincularam à (má) qualidade da educação, do ensino e da formação, enfatizando-se que a formação de professores, em particular a formação inicial, era pobre e insuficiente, o que produziu o chamado "argumento da incompetência” (Souza, 2006). Veicula-se, então, um discurso no qual "se estabelece uma relação direta entre (baixa) qualidade dos sistemas públicos de ensino e à (baixa) qualidade na formação docente" (Souza \& Sarti, 2014, p. 95), ao mesmo tempo em que "ressalta-se a centralidade dos professores nas sociedades contemporâneas" (Souza \& Sarti, 2014, p. 95).

É neste mesmo período que ocorre o movimento pela profissionalização do ensino, iniciado por um grupo de reitores de universidades americanas, inaugurando um novo modelo de formação docente (Holmes Group, 1986). Este modelo foi pautado, principalmente, na epistemologia da prática (Schön, 1992) - que será detalhada mais à frente -, a qual pressupõe revelar quais são e como os saberes são utilizados, mobilizados e integrados pelos docentes em suas tarefas cotidianas, bem como de que modo esses saberes são incorporados, produzidos e utilizados por eles (Tardif, 2013).

Assim, ao tomar a epistemologia da prática como base da formação de professores, inserese a docência em uma categoria profissional, e não mais vinculada a um ofício, pois, no "mundo do trabalho, o que distingue as profissões das outras ocupações é, em grande parte, a natureza dos conhecimentos que estão em jogo" (Tardif, 2013, p. 6). Assim, admitese que o movimento de profissionalização é uma tentativa de reconstruir os princípios e fundamentos que embasam o ofício do professor (Tardif, 2013).

Nessa lógica, se pensarmos especificamente nos cursos de formação inicial de professores, os conceitos de epistemologia da prática profissional e de profissionalização vinculamse diretamente à situação do estágio curricular e das práticas de ensino como aspectos centrais da formação. Neste caso, os saberes mobilizados pelos estagiários em situação concreta de prática pedagógica são considerados como pontos cruciais de reflexão, implicando posteriormente no processo de análise de práticas como base da formação (Altet, 2001).

Não obstante, o discurso que emerge em torno da profissionalização do ensino continua produzindo a polarização teoria e prática na maior parte dos cursos de formação inicial de professores no Brasil, nos levando a questionar: 1) Como a questão do estágio curricular supervisionado tem se manifestado na formação dos professores?; 2) As reformas propostas no âmbito da formação inicial docente a nível internacional e brasileiro, especificamente do estágio curricular, tomam a profissionalização como pressuposto?

Tais questões nos auxiliam na reflexão sobre os modelos de formação inicial atuais, que caminhos eles têm seguido no que tange à prática docente e de que modo os saberes docentes têm se articulado no momento do estágio. Neste último caso, deve haver o cuidado de não tornar esse momento da formação como mais uma disciplina da 
universidade, delegando a responsabilidade apenas para essa instituição. Deve constituir uma experiência de ensino que possibilite ao estagiário ressignificar suas concepções de escola, aluno e ensino, tornando-o mais reflexivo e questionador quanto às suas ações quando professor.

Pautado em uma reflexão teórica, o artigo que apresentamos dirige suas discussões ao movimento pela profissionalização do ensino (Holmes Group, 1986) em âmbito nacional e internacional, reconhecendo o estágio curricular supervisionado como o aspecto central desse processo. O texto está organizado em quatro secções que se concentram em apresentar: 1) uma breve retrospectiva das principais concepções da formação docente e sua relação com os saberes produzidos (ou não) pela profissão; 2) o movimento pela profissionalização docente e sua conceituação; 3) exemplos e experiências concretas, explorando o estágio curricular como centro e possibilidade do processo de profissionalização; e 4) algumas considerações finais.

1. DoCÊnCIA: UM “OFíCIO SEM SABERES”, “SABERES SEM OFÍCIO” OU UM “OFÍCIO FEITO DE SABERES”?

O termo 'saber' é amplamento utilizado na literatura sobre formação docente a fim de nomear o que os professores conhecem, possuem e se utilizam para atuar. No presente artigo, compreende-se o 'saber' docente sob a perspectiva de Tardif (2002), que o define como um conceito plural, individual e social, pertencendo a um contexto específico e a um sujeito. Assim, o termo 'saber' possui 'um sentido amplo, que engloba os conhecimentos, as competências, as habilidades (ou aptidões) e as atitudes, isto é, aquilo que muitas vezes foi chamado de saber, saber-fazer e saber-ser" (Tardif, 2013, pp. 10-11).
Nesse contexto, ao considerarmos a formação docente na perspectiva da profissionalização do ensino, faz-se necessário nos remetermos à trajetória histórica do "lugar" que os saberes dos professores e a formação prática ocupavam nas diferentes concepções, modelos de formação.

No Canadá, Gauthier et al. (1998) realizaram uma retrospectiva sobre esse processo, pontuando três principais momentos em que os saberes e sua relação com o ofício (ofício sem saberes; saberes sem ofício; ofício feito de saberes) foram focalizados. Para complementar tal discussão, nos remetemos a Tardif (2013) quando destaca três idades para o ensino vinculadas ao processo de profissionalização docente (idade do ensino como vocação; idade do ensino como ofício; idade do ensino como profissão). Com tais referenciais e outros que complementam tais ideias, é possível analisar a maneira pela qual a prática foi sendo vista nos três períodos discutidos e analisados pelos autores, apresentados nos itens a seguir.

\subsection{UM OFÍCIO SEM SABERES}

Entre os séculos XVII e XIX a docência foi reconhecida como um "ofício sem saberes" no Canadá (Gauthier et al., 1998), na França (Cousinet, 1974), em Portugal (Nóvoa, 1987), nos EUA (Hargreaves, 2000), bem como no Brasil (Cyrino, 2016). Não havia uma sistematização do que era necessário saber para ensinar (Tardif, 2013); a aprendizagem da docência era feita pela observação de um mestre mais experiente e por tentativa-erro (Cousinet, 1974; Cyrino, 2016; Gauthier et al., 1998; Hargreaves, 2000; Nóvoa, 1987; Tardif, 2013).

Partindo do contexto brasileiro e canadense, na "idade do ensino como vocação" (Tardif, 2013), para tornar-se professor bastaria ter um dom ou vocação, reconhecer este ofício como uma missão, ou ainda gostar de crianças. 
Havia os saberes-mestres, advindos da filosofia e doutrina cristã, os quais possuíam uma dimensão formadora e garantiam a sua ensinabilidade, legitimando o valor pedagógico do mestre, de seu ensino e de seus métodos.

Especificamente no Brasil, o professor "poderia se formar observando a ação modelar de outro docente da escola da Corte" (Vicentini \& Lugli, 2009, p. 31). Na França, a formação docente também era marcada por esses elementos, sendo pautada na observação e imitação de um bom professor experiente, e os iniciantes ministravam aulas baseadas na 'tentativa-erro' (Cousinet, 1974). Nóvoa (1987), nessa mesma época, em Portugal, ressalta que os denominados "mestres-escola", "sem nenhuma preparação para o exercício da atividade docente" (p. 418), permaneciam sob o controle da igreja. Assim, o ensino não deixa de ser visto como sacerdócio, uma profissão de fé.

\subsection{SABERES SEM OFÍCIO}

Com a modernização da própria sociedade, do século XIX ao início da segunda metade do século XX (Tardif, 2013), esse "modelo de cultura que integrava a produção de saberes e a formação baseada nesses mesmos saberes" (Tardif, 2002, p. 43) vai sendo eliminado em "benefício de uma divisão social e intelectual das funções de pesquisa”, assumidas por uma "comunidade científica ou por corpos de especialistas, e das funções de formação, assumidas por um corpo docente distanciado das instâncias de produção dos saberes" (Tardif, 2002, p. 43).

Em função dessa divisão social e intelectual, “os saberes técnicos e o saber-fazer vão sendo progressivamente sistematizados em corpos de conhecimentos abstratos" (Tardif, 2002, p. 43), separados dos grupos sociais de origem para serem "monopolizados por grupos de especialistas e de profissionais", sendo integrados a sistemas públicos de formação (Tardif, 2002, p. 43).

Assim, assiste-se a uma transformação da relação entre saber e formação e conhecimento e educação, havendo um deslocamento dos saberes para os procedimentos de transmissão dos saberes, ou seja, observa-se um progressivo enraizamento da pedagogia moderna nos saberes psicológicos e psicopedagógicos (Tardif, 2002). Essa questão aparece fortemente marcada do final do século XIX à primeira metade do século XX, tanto na França (Cousinet, 1974) quanto em Portugal (Nóvoa, 1987), Canadá (Gauthier et al., 1998), EUA (Hargreaves, 2000), Inglaterra (Connell, 2010), Brasil (Cyrino, 2016). Nesse contexto, adentrou-se no período em que Gauthier et al. (1998) consideram que o ensino é composto de saberes sem tomar como base o ofício, o que quer dizer que há "saberes que provocam o esvaziamento do contexto concreto de exercício do ensino" (p. 25). É composto por um corpo de conhecimentos que fundamenta a formação de professores externo àquilo que, de fato, eles realizam na sala de aula.

A formação de professores perde sua característica de formação geral para se transformar em formação profissional especializada, racionalizando a formação e a prática docente, podendo esta última ser associada a modelos de intervenção técnica, metodológica e profissional.

\subsection{UM OFÍCIO FEITO DE SABERES}

Com a ascensão das ciências da educação na segunda metade do século XX, há “uma transformação radical na relação entre educador e educando", na qual "o saber dos professores passa para o segundo plano, ficando subordinado a uma relação pedagógica centrada nas necessidades e interesses da criança e do educando" (Tardif, 2002, p. 45). São saberes "pertinentes em si mesmos, 
mas que nunca serão reexaminados à luz do contexto real e complexo da sala de aula" (Gauthier et al., 1998, p. 27).

Desse modo, os professores reforçam a crença de que o conhecimento especializado, advindo de pesquisas científicas, não sustenta a complexidade de suas práticas em sala de aula, contribuindo para "desprofissionalizar a atividade docente" (Gauthier et al., 1998, p. 27).

Porém, com o desenvolvimento dos sistemas escolares como instituições de massa, passase a exigir, em função da demanda de alunos em idade escolar, uma formação rápida de agentes e especialistas escolares, substituindo a ideologia da vocação por uma ideologia de caráter profissional centrada na profissão e em suas condições de trabalho, o que caracteriza a idade do ensino como ofício (Tardif, 2013). Com isso, instaura-se um paradoxo: se, de um lado, a formação pode contribuir para uma valorização social da profissão, por outro, observa-se que o espaço social do professor na escola passou a ser limitado e contestado no que tange ao atendimento das diferentes necessidades escolares.

Houve um reposicionamento da crítica sobre a formação de professores (Nóvoa, 1992; Shulman, 1987; Tardif, 2002), na qual se enfatizou a necessidade de considerar a docência em uma perspectiva profissional, produzir a vida do professor (Nóvoa, 1992, 1999), trabalhando-a de dentro para fora (Nóvoa, 2011). Reconhece-se, portanto, que a docência é um ofício feito de saberes (Gauthier et al., 1998) advindos da prática do professor em sala de aula: "É claro que basear o ensino no conhecimento do conteúdo, no 'bom senso', na experiência, na instituição, no talento ou numa vasta cultura não favorece de modo algum a formalização de saberes e habilidades específicos ao exercício do magistério" (Gauthier et al., 1998, p. 28).
Nessa perspectiva, a partir da segunda metade do século XX, inaugura-se a era da idade do ensino como profissão (Tardif, 2013), na formação de um profissional professor autônomo, bem como de um profissional colegiado, tendo como marco, nos EUA, a inauguração do movimento pela profissionalização do ensino e a publicação de Tomorrow's Teachers (Holmes Group, 1986). A formação de professores passa a ter centralidade no trabalho e na profissionalidade docente (Contreras, 2002), bem como na percepção do que o professor é e faz, visando conceber a docência como profissão (Tardif, 2002).

Connell (2010) assinala que, aos poucos, a formação foi sendo transferida para as universidades, que continuavam sendo "polos de educação humanista em meados do século XX” (p. 169). Nesse contexto, o modelo do profissional reflexivo (década de 70 do séc. $\mathrm{XX}$ ), vinculado a uma combinação de ideias humanistas com competências de ensino, corresponde, de modo geral, às concepções de uma "pedagogia crítica" e de professores como “intelectuais" (Connell, 2010, p. 169).

A prática e a compreensão de sua complexidade, a necessidade de refletir sobre as ações e analisar aquilo que se faz em sala de aula tornam-se elementos essenciais, trazendo à tona a ideia de profissionalização. Nesse sentido, evidencia-se que o saber da ação pedagógica, "legitimado pela pesquisa e pela própria atividade dos professores" (Gauthier et al., 1998, p. 35), poderia contribuir na formação inicial de professores, de modo que "refletiria melhor a prática no meio escolar, e o saber do próprio professor, difundido no seio da Universidade" (Gauthier et al., 1998, p. 35).

A fim de legitimar esse processo, surgem diversos outros enfoques para a formação docente, como, por exemplo, o modelo centrado no processo de aquisição de competências. Connell (2010) denomina de 
modelo de professor competente (década de 80 do séc. XX), equivalendo-se ao modelo de artesão competente (p. 169). Abandona-se a visão humanista, retornando a uma concepção técnica de professor, pois está “associado à expansão de uma ordem política e cultural direcionada aos interesses do mercado" (Connell, 2010, p. 169). Isto acaba por entrar em confronto com o ideal do profissionalismo.

A trajetória marcada pelos três momentos ora apresentados nos permite avançar nas discussões acerca do que de fato compõe a profissão docente e do processo de profissionalização do ensino, que visa, dentre outras questões, tornar a formação de professores mais estruturada e centralizada na profissão, no ambiente de trabalho. Além disso, nos auxilia a compreender que lugar a prática, os saberes docentes e, especificamente, o estágio curricular ganham nesse novo olhar para a formação.

\section{A PROFISSIONALIZAÇÃO DO ENSINO COMO PERSPECTIVA PARA A FORMAÇÃO DOCENTE}

A profissionalização do ensino começa a ser discutida academicamente no Brasil no final da década de 90 do séc. XX (Diniz-Pereira, 2013), mas tal processo iniciou-se no final dos anos 80, a partir de uma importante reforma na educação e, principalmente, na formação docente, que ocorreu no Canadá, França, Brasil, dentre outros países. Essas reformas, localizadas tanto em âmbito político, quanto em âmbito estrutural e simbólico, foram proponentes de um movimento com vistas a tornar a atividade do professor uma profissão.

Para Maués (2003), “as profissões formam comunidades unidas em torno dos mesmos valores e da mesma ética de serviço" (p. 100), incluindo-se nesse rol de características um estatuto profissional baseado em um saber científico e não somente prático (Dubar, 2009). Assim, dizer que a docência é uma profissão significa considerar

a passagem do ofício artesanal, em que se aplicam técnicas e regras, a uma profissão, em que cada um constrói suas estratégias, apoiandose em conhecimentos racionais e desenvolvendo sua especialização de ação na própria situação profissional, assim como sua autonomia. (Altet, 2001, p. 25)

Quando nos referimos à profissão, profissionalização, profissionalismo e profissionalidade implica considerar que há diversas vertentes que analisam tais conceitos partindo de diferentes olhares, como as perspectivas funcionalista, interacionista e interacionista-simbólica (Coelho \& DinizPereira, 2017). Na vertente funcionalista da sociologia das profissões, o principal critério que distingue uma profissão é o conhecimento especializado, os conhecimentos teóricos tidos como legitimadores desta e o "ideal de serviço" prestado à sociedade (Coelho \& Diniz-Pereira, 2017, pp. 8-12). No entanto, as análises funcionalistas limitam-se a separar "o saber profissional de suas condições de produção, de difusão e de utilização" (Chapoulie, 1973, p. 96). Já na perspectiva interacionista, os saberes são constantemente "construídos e negociados pelos profissionais ao longo de sua vida e carreira, nos contatos com os seus clientes e com quem trabalham" (Coelho \& Diniz-Pereira, 2017, p. 9), lembrando que estes saberes não têm que ser exclusivamente acadêmicos ou científicos. Porém, na abordagem interacionista-simbólica amplia-se o conceito de profissão sem deixar de apontar "a distância existente entre os 'saberes oficiais da profissão’ e as tarefas que os profissionais realmente fazem em sua prática" (Coelho \& Diniz-Pereira, 2017, p. 10). 
Nessas caracterizações, embora o termo profissionalização possa ser usado para designar "o processo segundo o qual um grupo profissional tende a se organizar segundo o modelo das profissões estabelecidas" (Chapoulie, 1973, p. 89), Larson (2014) aponta que a profissão é "uma forma historicamente específica de organizar o trabalho" (pp. 7-8) e que os professores são a "maior categoria de 'profissionais organizacionais' que servem o público" (p. 8), compreendendo o termo organizacional como distrito escolar, ou secretaria municipal de ensino (educação), no caso brasileiro.

No entanto, Coelho e Diniz-Pereira (2017) pontuam que alguns autores questionam a sedução do "discurso do profissionalismo" (Arroyo, 2000, p. 29, cit. em Coelho \& Diniz-Pereira, 2017, p. 21) ou a "retórica da profissionalização" (Contreras, 2002, p. 74, cit. em Coelho \& Diniz-Pereira, 2017, p. 21) tanto no que diz respeito à teoria dos traços (funcionalismo) quanto à perspectiva de alguém que vai olhar "no espelho dos outros" (Arroyo, 2000, p. 13, cit. em Coelho \& DinizPereira, 2017, p. 29). Como alternativa, resgatase a concepção do termo profissionalidade como "o conjunto de comportamentos, conhecimentos, destrezas, atitudes e valores que constituem a especificidade de ser professor" (Gimeno Sacristán, 1995, p. 64). Significa as "qualidades da prática profissional dos professores em função do que requer o trabalho educativo" (Contreras, 2002, p. 74), focalizando na especificidade do trabalho docente, como um conceito que permite ao professor olhar "no próprio espelho" (Arroyo, 2000, p. 13).

Assim, Tardif (2013), ao olhar também para o espelho da docência como profissão, passa a compreendê-la nas pegadas do movimento pela profissionalização do ensino (Holmes Group, 1986) na tentativa de renovar os fundamentos epistemológicos do ofício de professor. Pressupõe-se, portanto, um professor profissional que seja autônomo e responsável, que saiba explicitar suas ações e práticas de forma sistematizada e racional (Altet, 2001).

O Holmes Group foi um dos pioneiros desse processo ao propor uma reforma na formação dos professores, dando destaque para a construção de uma base de conhecimentos especializados próprios dos professores. Nesse sentido, a ideia de profissão toma corpo. Ao elaborar o relatório Tomorrow's Teachers, o Holmes Group (1986) introduziu um novo paradigma pautado na ideia de profissão proveniente da cultura angloamericana, advogando a emergência de um perfil profissional dos professores a partir da estruturação de sua carreira. A proposta enfatiza a importância de uma formação inicial de alto nível centrada na escola e a formação continuada construída e acompanhada pelos próprios pares.

\subsection{A UNIVERSITARIZAÇÃO COMO PERSPECTIVA DE PROFISSIONALIZ AÇ Ã O}

A formação inicial dos professores, que era majoritariamente realizada em nível médio nas escolas normais e depois em cursos de Magistério, passou a ser acolhida por universidades, faculdades, centros universitários, dentre outras instituições de ensino superior. Este processo passou a ser nomeado de universitarização (Bourdoncle, 2007). Negando a formação artesanal, tecnicista e aplicacionista, este novo modelo de formação valoriza os saberes científicos e acadêmicos, formando professores com base na cultura universitária. Pressupõe, portanto, formar um profissional crítico e reflexivo, a partir de conteúdos professados. 
Com a universitarização da formação assumese um caráter eminentemente mais científico e profissional, no qual as áreas de Ciências Sociais e Humanas emergiram com força. No entanto, este processo é considerado arriscado, pois, mesmo tendo a intenção de elevar o nível de instrução dos professores, o espaço que ocupa (universidade) não é, possivelmente, capaz de profissionalizar os docentes, formando-os, então, nos moldes universitários, com ênfase em discursos e práticas acadêmicas. Esta é a crítica trazida por Formosinho (2009), que, reconhecendo a universitarização como um conceito descritivo, traz como contrapartida a utilização do termo "academização" dos professores. Neste sentido, o autor aponta que, apesar de a formação docente ocorrer em nível superior, acaba por inserir os futuros docentes em uma cultura acadêmica, oferecendo-lhes poucas possibilidades de desenvolvimento do trabalho colaborativo e interdisciplinar, bem como a cooperação entre pares, o largo contato com a realidade escolar, dentre outros elementos importantes para o trabalho do professor no espaço escolar.

2.2 A Lógica PRofissional DE FORMAÇÃO: UMA POSSIBILIDADE PARA A PRofissionalizaÇão doCENTE

Compreendemos que, alterando o lugar de formação, mudou-se também a concepção de formação, os conteúdos, a estrutura curricular e o modo como a prática do ensino passou a ser concebida, estruturada e desenvolvida. O currículo ganhou relevância junto à ideia de uma epistemologia da prática (Schön, 1992), pautada em uma racionalidade prática, contrapondo-se ao currículo baseado na racionalidade técnica.

Schön (1992), baseando-se nos estudos de John Dewey, ao difundir o conceito de epistemologia da prática, focaliza a reflexão como aspecto central da formação profissional. Nessa perspectiva, o autor prevê dois principais momentos durante e após a prática docente: reflexão na ação (quando o professor, com experiência em sala de aula, necessita tomar decisões rapidamente, 'no fogo da ação', utilizando-se de um repertório de decisões que já possui) e reflexão sobre a reflexão na ação (quando o professor toma distância da ação, tentando explicá-la, descrevê-la e fundamentála) (Schön, 1992, 1993).

Assim, se antes a prática era desenvolvida na forma artesanal e imitativa, passando para uma maneira aplicacionista e tecnicista, chegase atualmente na ideia de estágio curricular supervisionado como prática reflexiva, na qual se possibilita ao futuro professor vivenciar e experenciar o cotidiano escolar. Essa concepção de estágio pautada na ideia de profissionalização docente traz consigo inúmeros desafios para seu desenvolvimento, como, por exemplo, reunir equipes de professores da escola campo e da universidade como responsáveis pela formação de futuros professores, auxiliando-os nesse processo de reflexão e análise do ensino, dois elementos importantes para a profissionalização (Altet, 2001).

Porém, para que, de fato, o estágio curricular possa seguir a concepção da formação profissional, saindo do discurso acadêmico e partindo para uma postura profissional, é necessário que dois movimentos se encontrem: "uma maior proximidade da formação com as práticas profissionais docentes, com a consideração da escola como locus formativo privilegiado" e "a elevação do nível de certificação dos professores acompanhando a elevação do nível educacional da população" (Sarti, 2013a, p. 218).

Assim, passa-se a olhar para a formação de professores de outro lugar, considerando a socialização e o desenvolvimento profissional 
(Marcelo, 1999) como um novo marco para se compreender a profissão docente, o currículo de formação, o trabalho docente, as competências profissionais, a escola e a família como fundantes de um habitus, o habitus de professor (Silva, 2009).

Portanto, a formação docente, nessa perspectiva, se caracteriza como "um processo de socialização, que deve possibilitar ao sujeito organizar os saberes aprendidos para serem empregados em situação de ensino" a partir de uma "integração entre o local de trabalho e a formação docente" (Sarti, 2013a, p. 218); a "escola, enquanto espaço onde os saberes docentes são mobilizados, passa a ser considerada central para a formação do magistério, enquanto se espera que os professores experientes assumam uma nova identidade, como formadores de seus pares", seguindo uma lógica socioprofissional (Sarti, 2013a, p. 219).

Como pode ser observado, nesse novo processo, o trabalho docente, as práticas, a experiência dos professores e a escola, enquanto partícipe na formação dos futuros professores, são aspectos que passam a ser mais valorizados, potencializando o papel do estágio curricular nos cursos de formação inicial.

\subsection{As ROTAS ALTERNATIVAS NO} PROCESSO DE PROFISSIONALIZAÇÃO

Não podemos deixar de mencionar que, em oposição ao movimento da profissionalização, mas utilizando-se desse mesmo discurso, há um mercado da formação que visa criar "rotas alternativas" (Zeichner, 2013) ou "caminhos alternativos" (Nóvoa, 2017) para a formação inicial. Tal é o caso dos EUA, onde "desde os anos de 1990, tem havido um aumento exponencial de programas de formação de professores que não são oferecidos por faculdades e universidades" (Zeichner, 2013, p. 20). Cada vez mais as pessoas têm se inserido no magistério por estas vias, "às vezes com muito pouca ou nenhuma preparação antes de assumir total responsabilidade por uma sala de aula” (Zeichner, 2013, p. 20). São programas nos quais os professores ingressam na forma de uma 'imersão', ou seja, "completam a maior parte de sua formação para o magistério enquanto trabalham como professores designados, totalmente responsáveis por sala de aula" (Zeichner, 2013, p. 22).

Assim, por um lado, corremos o risco de que a profissionalização dos professores caia na dimensão de um ofício sem saberes e, por outro, enfrentamos o dilema de se ter saberes sem ofício. Gauthier et al. (1998) assinalam que "basear o ensino no conhecimento do conteúdo, no 'bom senso', na experiência, na intuição, no talento ou numa vasta cultura não favorece de modo algum a formalização de saberes e de habilidades específicas ao exercício do magistério" (p. 28).

É necessário, portanto, construir um novo lugar institucional fortemente ancorado na universidade, um "lugar híbrido", de encontro e de junção das várias realidades que configuram o campo docente, mas com fortes ligações externas, para cuidar da formação de professores (Nóvoa, 2017). De qualquer maneira, com a conceituação e problemática apresentadas, para além do discurso eminentemente teórico, há muitos programas de formação docente que se utilizam de elementos de formação que se aproximam de um modelo de formação profissional.

$\mathrm{Na}$ próxima seção apresentaremos alguns exemplos que nos permitem repensar a formação docente, tomando o estágio curricular como aspecto central e possível para a profissionalização do ensino. 


\begin{tabular}{lcr} 
3. & MODELO & \multicolumn{2}{c}{ PROFISSIONAL } \\
DE $\quad$ FORMAÇÃO: & O r ESTÁGIO \\
SUPERVISIONADO & & COMO \\
PROTAGONISTA & &
\end{tabular}

Nos tópicos anteriores pudemos acompanhar a trajetória da formação docente, momento em que enfatizamos o lugar que o saber e a prática ocuparam em cada período, até chegarmos ao processo de profissionalização docente. Neste item exploramos a centralidade da prática e do espaço escolar enquanto aspectos principais dos modelos profissionais de formação.

Atualmente a concepção de prática de ensino pressupõe uma formação docente que articule os conhecimentos da Universidade e da Escola, exigindo a participação direta de outros atores sociais como o professor da escola que recebe o estagiário. Em alguns países europeus, como França, Bélgica e Suíça, esse docente é reconhecido como um "formador". Além desses atores, tal concepção engloba ainda dispositivos de formação utilizados com e pelos estudantes, a fim de analisarem suas práticas, seguindo a perspectiva da prática reflexiva (Schön, 1993), como já pontuamos em outros momentos do artigo.

Nesse sentido, reconhecida como estágio supervisionado, a prática contempla o processo de acolhimento e de acompanhamento (Cyrino, 2016; Sarti \& Araújo, 2016), envolvendo tanto Escola como Universidade.

Essa formação pelo acompanhamento rompe com o modelo mais tradicional de formação docente, representado pelo antigo mestre de aplicação das Escolas Normais (professor 'exemplar' a ser imitado pelos futuros professores). Não se trata mais de observar o modelo para aplicá-lo às situações de ensino, mas de experimentar o trabalho docente sob a orientação de um formador capaz de empregar dispositivos formativos que ofereçam suporte, face a face, a um iniciante ou a um profissional menos experiente, a fim de que ele descubra suas próprias possibilidades de atuação. (Sarti, 2013a, p. 219)

Tal perspectiva corresponde ao modelo de formação profissional, que pode ser identificado em diferentes países, como Suíça, Bélgica, Canadá, França, Portugal. A fim de aprofundar e apresentar elementos concretos da formação profissional, elencamos três contextos que possuem os seguintes aspectos relacionados à formação profissional: sistematização do estágio curricular como uma experiência de formação; formalização do papel de um profissional da escola como alguém que acompanha o estagiário; a prática como elemento central do processo de formação, levando-se em consideração a reflexão e sua análise.

Os contextos escolhidos são: a) França, na proposta de um modelo de formação nacional; b) Canadá, província de Quebec, na perspectiva de um modelo francófono, com influência anglo-americana; c) Brasil, onde não há um modelo de estágio nacional definido enquanto concepção teórica, nem mesmo estadual; no entanto, ao realizar a busca pelos critérios mencionados acima, encontramos experiências que se aproximam de um modelo profissional de formação, localizadas no Estado de São Paulo (Cyrino \& Souza Neto, 2014).

Cabe ressaltar que, considerando a trajetória da formação de professores no Brasil no século $\mathrm{XX}$, tomamos como base a influência francesa e canadense, por essa última trazer subjacentes contribuições da perspectiva do movimento pela profissionalização do ensino no que diz respeito a epistemologia da prática. Assim, sem a intenção de realizar uma comparação entre os modelos, principalmente porque estão localizados em contextos socioeconômicos 
e políticos distintos, o objetivo de tal apresentação é oferecer uma reflexão sobre as possibilidades de formação profissional do professor, tendo como perspectiva o estágio curricular.

3.1 Contextos DE ESTÁgIO Supervisionado：França, Canadá (QUEBEC) E BRASIL

O CONTEXTO FRANCÊS: PROPOSTA DE UM MODELO NACIONAL DE FORMAÇÃO DE PROFESSORES

A França tem investido na preparação dos professores desde o início dos anos 90 do séc. $\mathrm{XX}$, quando criou os Institutos Universitários de Formação de Mestres (Instituts Universitaires de Formation dês Maîtres IUFM). Atualmente extintos, os IUFM foram institutos que se constituíam em um modelo de formação com uma proposta que articulava "uma ambição acadêmica (estabelecimentos universitários) e uma ambição prática/ profissional (institutos de formação inicial de professores)" (Duran, Saury, \& Veyrunes, 2005, p. 40), reconhecendo esse processo como um dispositivo de profissionalização (GonninBolo, 2003).

A partir de 2008, estes institutos foram vinculados às universidades, e, por conta do processo de Bolonha, a formação docente foi elevada ao nível de mestrado, passando, portanto, pela Masterisation (Jolion, 2011). Assim, os estudantes que desejavam a carreira docente deveriam finalizar o Baccalauréat (licenciatura no Brasil) e posteriormente cursavam dois anos de mestrado, momento em que realizavam seu estágio profissional.

Atualmente, a formação de professores na França ocorre nas ESPE (Écoles Supérieures du Professorat et de l'Éducation), escolas que visam uma formação com forte dimensão profissional em nível de mestrado, que tem no centro do currículo a prática profissional e os estágios curriculares. Nestes, os estagiários passam por três momentos principais: um tempo de preparação; uma fase de exploração; análise reflexiva, momento em que os estagiários se debruçam sobre suas vivências no estágio e realizam um processo de confrontação com sua prática articulando às teorias. Todo esse processo é acompanhado por um formador, professor da escola que se responsabiliza pela formação do estagiário.

O CONTEXTO CANADENSE: O MODELO CURRICULAR PROFISSIONAL DA PROVÍNCIA DO QUEBEC

No Canadá há experiências que se diferenciam de uma formação pautada no modelo acadêmico, ou seja, aquele em que a formação prática ocorre no final do curso e os estágios são desconexos ou desvinculados do âmbito teórico. A Universidade de Montréal (Quebec) possui um currículo de formação pautado no modelo curricular profissional de formação, no qual a prática é o centro do currículo, contemplando um Centro de Formação do Mestre, que ampara esse processo, e um modelo de estágio em alternância, que consiste em períodos de inserção no meio escolar e períodos de formação na Universidade (Borges, 2008).

Do ponto de vista organizacional, esse estágio curricular acontece desde o primeiro ano de formação (primeiro ciclo ou graduação), no qual ocorre a inserção gradual do estudante no meio escolar (Gervais \& Correa Molina, 2008).

Os estudantes realizam quatro estágios: (a) familiarização e assistência no ensino primário; (b) familiarização e assistência no ensino secundário; (c) ensino primário; e (d) ensino secundário. Para cada estágio, há um professor-associado (formador, cooperante) que recebe o estagiário e um supervisor 
universitário que é responsável pela supervisão. Há momentos do estágio em que o supervisor, o professor-associado e o estagiário discutem sobre os avanços do estudante, promovendo orientações e, ao mesmo tempo, o avaliando durante o período de estágio (Lepage, Gervais, \& Malo, 2018).

O CONTEXTO BRASILEIRO: AS TENTATIVAS DE PROFISSIONALIZAÇÃO DO ENSINO NO ESTÁGIO

No Brasil, o estágio e a prática ainda não são reconhecidos como aspectos centrais do currículo de formação nos projetos dos cursos de licenciatura (Gatti \& Nunes, 2009), mesmo que a legislação tenha avançado sob tal perspectiva (Resolução $n^{\circ} 2$, de 1 de julho de 2015). Na maioria dos casos, o estudante realiza o estágio entre o meio universitário e escolar a partir de um planejamento de ensino elaborado em conjunto com a escola e o professor da área de ensino.

Nesse processo, o estudante vai de uma a duas vezes por semana na escola para fazer o estágio, tendo como orientação legal desenvolvê-lo a partir da segunda metade de sua formação inicial, predominando o modelo disciplinar de formação da racionalidade técnica. Há pouco apoio institucional e, não possuindo um modelo nacional formalizado de estágio, prevalece também uma perspectiva mais artesanal ou aplicacionista (Cyrino, 2016).

Apesar disso, encontramos experiências no Estado de São Paulo que avançam e se aproximam da ideia de formação profissional, quando:

a. optam pelo trabalho colaborativo na UNESP/Rio Claro com professores da escola e redes de ensino (Souza Neto \& Benites, 2013), desenvolvendo em casos específicos a Parceria Intergeracional na Pedagogia, que traz a ideia de uma relação duplamente formativa na qual há o encontro entre duas gerações na profissão docente - o estagiário como iniciante e o professor da escola (Sarti, 2013b);

b. priorizam um trabalho sistematizado nos estágios curriculares (Cyrino \& Souza Neto, 2017), como na proposta da UNIFESP com a Residência Pedagógica, que é "inspirada na experiência da tradição de formação médica", incorporando "o princípio da imersão", definido como um "processo de contato sistemático e temporário com práticas profissionais reais", envolvendo Universidade e Escola na formação inicial de professores na Pedagogia (Giglio \& Lugli, 2013, p. 65);

c. se opta pela incorporação de dispositivos (instrumentos que possibilitam diretamente ao estagiário refletir sobre suas ações e sua prática em sala de aula) voltados ao acompanhamento de estagiários na Pedagogia - UNESP/Rio Claro, possibilitando que professores possam acompanhar o desenvolvimento profissional do estudante de licenciatura (Cyrino, 2016);

d. se desenvolvem também dispositivos para acompanhar os estagiários em formação inicial na Educação Física - UNESP/Rio Claro - compostos por uma check-list envolvendo: competências relacionadas às qualificações pessoais; habilidades de ensino e gestão da classe; habilidades de comunicação e interação; e a aula (Souza Neto \& Iaochite, 2015), devendo ser observadas e avaliadas (Souza Neto \& Benites, 2013).

Pudemos observar um grande esforço das IES em inserir a escola, valorizar a docência e as experiências práticas no processo de formação (Borges, 2008; Souza Neto, Sarti, \& Benites, 2016), superando aos poucos os desafios colocados no Brasil para a formação docente (Iza \& Souza Neto, 2015). Para além destas questões, é importante sinalizar que tais propostas caminham na perspectiva 
da profissionalização (Borges, Souza Neto, Sarti, \& Benites, 2013) quando decidem pela parceria com professores da escola e redes de ensino (Souza Neto \& Benites, 2013), quando há a preocupação com a formação inicial no local da atividade docente (Cyrino \& Souza Neto, 2014) e no momento em que optam por um trabalho sistematizado nos estágios curriculares (Cyrino \& Souza Neto, 2017).

4. A Título de CONCLUSÃo, POR UMA PEDAGOGIA DA FORMAÇÃO NO ESTÁGIO SUPERVISIONADO

Para o desenvolvimento deste texto trabalhamos com duas questões de investigação: 1) Como a questão do estágio curricular supervisionado tem se manifestado na formação dos professores?; 2) As reformas propostas no âmbito da formação inicial docente a nível internacional e brasileiro, especificamente do estágio curricular, tomam a profissionalização como pressuposto? Nesse contexto, pensar a formação prática dos estudantes significou: fazer um diálogo com a docência na trajetória de um ofício que busca se tornar uma profissão; desenvolver uma reflexão sobre a profissionalização do ensino como perspectiva de promoção da formação docente; e identificar o lugar do estágio curricular no modelo profissional de formação.

Assim sendo, nesta última parte do texto daremos maior atenção às reformas desenvolvidas no âmbito da formação inicial docente - especificamente, no campo do estágio curricular -, tomando a profissionalização como pressuposto. Buscamos, nas premissas da profissionalização do ensino e das reformas, alguns indicativos que possam nos ajudar a compreender melhor essa mudança de paradigma, considerando i) a docência como profissão na formação inicial e ii) o estágio curricular nas reformas do ensino.

\subsection{A DOCÊNCIA COMO PROFISSÃO} NA FORMAÇÃO INICIAL

No corpo do texto foi assinalado que, no processo de profissionalização do ensino, duas características eram fundamentais: a existência de um saber científico e o fato de esse saber ser desenvolvido na universidade (Maués, 2003). Dessa forma, a docência como profissão, na formação de novos quadros, prescinde do desenvolvimento profissional (Libâneo \& Pimenta, 1999), assim como do desenvolvimento de uma cultura profissional e de uma identidade da profissão (Cardoso, Batista, \& Graça, 2016). Esta perspectiva incita a que a formação docente siga uma lógica socioprofissional, que incorpora um processo de socialização, possibilitando ao sujeito pensar e organizar os saberes aprendidos para serem empregados em situação de ensino, facilitando a integração entre o local de trabalho e a formação docente.

No geral, a profissionalização do ensino, norteada pelas políticas educacionais, altera significativamente o trabalho, a formação e a carreira docente (Sarti, 2012), posto que integra um amplo movimento de reformas dirigido também por organismos internacionais (Maués, 2003). Portanto, ao longo do século $\mathrm{XX}$, diversos países empreenderam "reformas educacionais que previam a elevação do nível de formação dos professores das séries elementares" (Sarti, 2012, p. 325). Esse foi o caso dos Estados Unidos na década de 1930, do Canadá e da Inglaterra nos anos 1960, da Austrália nos anos 1970, do México na década de 1980 e da França nos anos 1990 (Bourdoncle, 2000). Nos anos 2000, a própria Comunidade Europeia estabeleceu que a formação docente deveria ser elevada ao nível de mestrado, totalizando cinco anos de estudos 
universitários, como já ocorria em alguns países do norte da Europa (Chartier, 2010). No contexto brasileiro, a elevação do nível de formação dos professores foi impulsionada por uma diretriz nacional que passou a exigir a formação superior para todos os professores da educação básica, bem como apontar para a formação dos profissionais da educação (Lei $n^{\circ}$ 9.394, de 20 de dezembro de 1996).

\subsection{O ESTÁGIO CURRICULAR NAS REFORMAS DO ENSINO}

Com base em diferentes autores, Borges et al. (2013) assinalam que, desde a década de 1990, a formação docente vem passando por transformações em relação ao lugar, às modalidades e à duração dos estágios curriculares ao longo da formação inicial. No âmbito desse processo, que envolve a universitarização e a masterização do magistério, essas mudanças provocam uma acentuada valorização dos saberes acadêmicocientíficos para a docência.

Mas estas transformações, que estão na base do discurso sobre a profissionalização, podem assumir também formatos específicos em função das características de cada país e de cada contexto universitário, pois o ponto para o qual elas convergem é o de considerar a prática profissional como um locus de produção e de formação nos saberes (Tardif, Lessard, \& Gauthier, 1998).

No entanto, esse processo não para no movimento pela profissionalização do ensino, mas assume destaque também outro movimento que coloca a experiência prática no centro da formação dos professores (Sarti, 2012), introduzindo, com Donald Schön, uma pedagogia da formação (Ghedin et al., 2015) pautada na ideia de racionalidade prática. Sarti (2012) observa que, embora essas duas tendências fossem concorrentes, em alguns sentidos elas coexistiam "em certos contextos nos quais se buscou um caminho intermediário, capaz de aliar a elevação do nível da formação à ênfase na prática docente" (p. 326). Esse movimento também influenciou na formulação de novos currículos de formação, assim como trouxe uma revisão da prática pedagógica e da experiência prática, impactando na prática de ensino do estágio supervisionado. A prática se torna lugar de formação e produção de saberes, bem como de desenvolvimento de competências profissionais (Borges, 2008).

Nessa direção, de um lado, os docentes são tomados como "profissionais reflexivos, capazes de deliberar sobre suas práticas, de objetivá-las, de inová-las, de torná-las mais eficazes e acessíveis aos pares" (Borges et al., 2013, p. 1); de outro, "a prática passa a ser considerada como um espaço original e relativamente autônomo de aprendizagem e de formação dos futuros docentes" (Borges et al., 2013, p. 1). Concretamente, isso deu origem, em alguns países, à adoção de um modelo dual e de alternância na formação inicial com uma base em dispositivos formativos (roteiros de acompanhamento da formação), buscando alternar teoria e prática, num vai-e-vem entre a universidade e o meio escolar (Chochard \& Mazalon, 2016). Portanto, ele visa favorecer vínculos mais estreitos entre a experiência de campo e a teoria oriunda da pesquisa, os docentes e os estagiários.

Assim, diversas transformações ocorreram nos contextos apresentados neste artigo. No Quebec, Canadá francês, com o desenvolvimento de um modelo curricular centrado na prática, promovendo a escola como lugar de formação e o estágio curricular como o eixo da formação docente (Borges, 2008; Gervais \& Desrosiers, 2005; MELS, 2004). No Brasil, as reformas centraram-se nos normativos legais (Lei $\mathrm{n}^{\circ} 11.788$, de 25 de setembro de 2008; Resolução no 1 de 2002; 
Resolução no 2 de 2015), os quais definem carga horária de realização de estágio e destacam a escola como lugar de formação e seus agentes como partícipes do processo. Já na França, optou-se pela formação profissional de dois anos em nível de mestrado, no qual os estudantes, após terem seguido uma formação pedagógica no primeiro ano, realizam o estágio (Jolion, 2011).

Todas estas transformações e apropriações nacionais e internacionais têm avançado a passos largos, mas os efeitos das mesmas sobre os programas de formação, sobre as práticas dos formadores e sobre os estudantes que as vivem são pouco conhecidos. Estas mudanças, em curso no Brasil, em transformação na França e em Portugal, e já bem consolidadas em Quebec, trazem novos desafios aos formadores $\mathrm{e}$ às instituições que assumem e asseguram a formação de futuros docentes.

Ao ponderar tais aspectos, consideramos a ideia de projetar o estágio na perspectiva de uma pedagogia da formação, como propõe Nóvoa (2012) quando se refere à formação docente na universidade. Para o autor, há quatro iluminações que podem auxiliar a desenvolver uma pedagogia universitária: Investigação Grupos de Pesquisa; Colaboração; Pedagogia Situacional e Cultura Profissional; Experiência. As três últimas iluminações têm vínculo direto com nosso texto e nos permitem pensar o estágio no âmbito da profissionalização do ensino.

A primeira possibilidade aponta para uma pedagogia baseada em práticas de colaboração, trabalho em equipe, ou seja, que se faz junto por meio do diálogo, constituindo redes sociais (Nóvoa, 2012). No caso do estágio, as relações de diálogo são baseadas na perspectiva da parceria entre universidade e escola como coformadoras. A segunda possibilidade vem marcada por uma pedagogia que valorize a situação (pedagogia da imprevisibilidade) e a cultura profissional. Valoriza-se também a aprendizagem numa pedagogia situacional, envolvendo práticas de uma cultura mais ativa, nas quais os estagiários identifiquem e analisem aspectos do ensino, da realidade escolar, do trabalho docente e da cultura do magistério. Por fim, uma pedagogia que valorize também as dimensões experienciais dentro e fora dos muros da universidade, permitindo aos futuros professores que, ao ampliar as experiências e vivências dos aspectos do trabalho docente e da realidade escolar, possam estabelecer diálogos mais consistentes, pois necessitamos "construir lógicas de formação que valorizem a experiência como aluno, como aluno-mestre, como estagiário, como professor principiante, como professor titular e, até, como professor reformado" (Nóvoa, 1999, p. 15).

Concluindo, há a necessidade de uma pedagogia que vá além da tradição e não se feche no conhecimento. Uma pedagogia que seja capaz de valorizar uma experiência que inclua a reflexão social (Nóvoa, 2012). Neste sentido, a formação de professores pode ser pensada a partir de um modelo híbrido (Zeichner, 2010) que envolva os conhecimentos acadêmicos, empíricos e sociais, pois é necessário considerar a escola e suas contribuições. Caso contrário, o futuro professor continuará, na maioria dos casos, a ser lançado em sua prática isoladamente e a exercer a sua profissão no âmbito de uma privatização de sua prática.

\section{REFERENCIAS}

Altet, M. (2001). As competências do professor profissional: Entre conhecimentos, esquemas de ação e adaptação, saber analisar. In L. Paquay, P. Perrenoud, M. Altet, \& E. Charlier (Orgs.), Formando professores profissionais. Quais estratégias? Quais competências? (2a ed., pp. 23-35). Porto Alegre, Brasil: Artmed. Arroyo, M. G. (2000). Ofício de mestre - 
Imagens e auto-imagens ( $7^{\mathrm{a}}$ ed.). Petrópolis, RJ, Brasil: Editora Vozes.

Borges, C. (2008). A formação docente em Educação Física em Quebec: Saberes, espaços, culturas e agentes. In C. Traversini, R. Eggert, E. Peres, \& I. Bonin (Orgs.), Anais XIV ENDIPE (livro 2): Trajetória e processos de ensinar e aprender: Práticas e didáticas (pp. 147-174). Porto Alegre, RS, Brasil: EDIPUCRS.

Borges, C., Souza Neto, S., Sarti, F. M., \& Benites, L. C. (2013). Os desafios da prática como lócus central da formação inicial docente: Novos dispositivos e agentes, novas modalidades e supervisão pedagógica (Apresentação do Dossiê). Cadernos de Educação, 46, 1-5. Recuperado de https:// periodicos.ufpel.edu.br/ojs2/index.php/ caduc/article/view/4168

Bourdoncle, R. (2000). Professionnalisation, formes et dispositifs. Recherche et Formation, 35, 117-132.

Bourdoncle, R. (2007). Autour du mot «Universitarisation». Recherche et Formation, 54, 135-149. https://dx.doi. org/10.4000/rechercheformation.945

Cardoso, M. I. S., Batista, P. M. F., \& Graça, A. B. S. (2016). A identidade do professor: Desafios colocados pela globalização. Revista Brasileira de Educação, 21(65), 371-390. http://dx.doi.org/10.1590/S1413$\underline{24782016216520}$

Chapoulie, J. M. (1973). Sur l'analyse sociologique des groupes professionnels. Revue Française de Sociologie, 14(1), 86-114.

Chartier, A.-M. (2010). A questão da língua materna na formação continuada entre os anos 1970 e 2010 na França. In A. T. B. Ferreira \& S. P. S. Cruz (Orgs.), Formação continuada de professores: Reflexões sobre a prática (pp. 53-67). Recife, Brasil: Editora da UFPE.

Chochard, Y., \& Mazalon, E. (2016). Stages en entreprise en formation duale et alternée: Quatre paramètres à considérer. Bulletin OCE (Observatoire Compétences-Emploi), 7(2). Recuperado de https://oce.uqam.ca/ article/stages-en-entreprise-en-formationduale-et-alternee-quatre-parametres-aconsiderer/

Coelho, A. M. S., \& Diniz-Pereira, J. E. (2017). Olhar o magistério "no próprio espelho": O conceito de profissionalidade e as possibilidades de se repensar o sentido da profissão docente. Revista Portuguesa de Educação, 30(1), 7-34. https://dx.doi. org/10.21814/rpe.10724

Connell, R. (2010). Bons professores em um terreno perigoso: Rumo a uma nova visão da qualidade e do profissionalismo. Educação e Pesquisa, 36(spe), 165-184. https://dx.doi. org/10.1590/S1517-97022010000400013

Contreras, J. (2002). A autonomia de professores. São Paulo, Brasil: Cortez.

Cousinet, R. (1974). A formação do educador e a pedagogia da aprendizagem. São Paulo, Brasil: EDUSP/Nacional.

Cyrino, M. (2016). Do acolhimento ao acompanhamento compartilhado: $A$ construção colaborativa de uma proposta para o estágio curricular no curso de pedagogia (Tese de doutorado, UNESP). Recuperado de http://hdl.handle.net/11449/137997

Cyrino, M., \& Souza Neto, S. (2014). O estágio curricular supervisionado na experiência brasileira e internacional. Revista Educação em Questão, 48(34), 86-115. Recuperado de http://www.periodicos.ufrn.br/ educacaoemquestao/article/view/5731

Cyrino, M., \& Souza Neto, S. (2017). Parceria universidade e escola no estágio curricular: Um processo em constituição. Revista Diálogo Educacional, 17(52), 661-682. Recuperado de https://periodicos.pucpr. br/index.php/dialogoeducacional/article/ view/9945/12437 
Diniz-Pereira, J. E. (2013) A construção do campo da pesquisa sobre formação de professores. Revista da FAEEBA - Educação e Contemporaneidade, 22(40), 145-154. https://www.revistas.uneb.br/index.php/ faeeba/article/view/758/531

Dubar, C. (2009). A crise das identidades. A interpretação de uma mutação. São Paulo, Brasil: Editora da Universidade de São Paulo.

Duran, M., Saury, J., \& Veyrunes, P. (2005). Relações fecundas entre pesquisa e formação docente: Elementos para um programa. Cadernos de Pesquisa, 35(125), 37-62. Recuperado de http://www.scielo.br/pdf/cp/ v35n125/a0435125.pdf

Formosinho, J. (2009). Academização da formação de professores. In J. Formosinho (Coord.), Formação de professores: Aprendizagem profissional e acção docente (pp. 73-92). Porto: Porto Editora.

Gatti, B. A., \& Nunes, M. M. R. (2009). Formação de professores para o ensino fundamental: Estudo de currículos das licenciaturas em Pedagogia, Língua Portuguesa, Matemática e Ciências Biológicas. Coleção Textos FCC, vol. 29. INEP. Resumos Técnicos - Censo da Educação Superior de 2010, 2011, 2013.

Gauthier, C., Martineau, S., Desbiens, J-F., Malo, A., \& Simard, D. (1998). Por uma teoria da pedagogia. Ijuí, Rio Grande do Sul, Brasil: UNIJUÍ.

Gervais, C., \& Correa Molina, E. (2008). Les stages en formation à l'enseignement : Pratiques et perspectives théoriques. SainteFoy, Québec: Presses de l'Université du Québec.

Gervais, C., \& Desrosiers, P. (2005). Lécole, lieu de formation d'enseignants: Questions et repères pour l'accompagnement de stagiaires. Sainte-Foy, Québec: Presses de l'Université Laval.

Ghedin, E. (2009) Tendências e dimensões da formação de professores na contemporaneidade. In J. A. V. Palma, A. P. T. V. Palma, \& A. C. Saladini (Orgs.), Anais $4^{\circ}$ CONPEF: Modos de ser professor (pp. 1-28). Londrina, PR, Brasil: UEL.

Ghedin, E., Oliveira, E. S., \& Almeida, W. A. (2015). Estágio com pesquisa. São Paulo, Brasil: Cortez.

Giglio, C. M. B., \& Lugli, R. S. G. (2013). Diálogos pertinentes na formação inicial e continuada de professores e gestores escolares. A concepção do Programa de Residência Pedagógica na UNIFESP. Cadernos de Educação, 46, 62-82. Recuperado de http://periodicos.ufpel.edu. br/ojs2/index.php/caduc/article/view/4173

Gimeno Sacristán, J. (1995). Consciência e acção sobre a prática como libertação profissional dos professores. In A. Nóvoa (Org.), Profissão professor (pp. 63-92). Porto, Portugal: Porto Editora.

Gonnin-Bolo, A. (2003). De l'ENNA à l'IUFM : Le deuil difficile d'une culture communautaire. Revue Française de Pédagogie, 142, 69-77. Recuperado de http://www.persee.fr/web/revues/home/ prescript/article/rfp 0556-7807 2003 num \begin{tabular}{lll}
142 & 1 & 2933 \\
\hline
\end{tabular}

Hargreaves, A. (2000). Four ages of professionalism and professional learning. Teachers and Teaching, 6(2), 151-182. https://doi.org/10.1080/713698714

Holmes Group. (1986). Tomorrow's teachers: A report of the Holmes Group. East Lansing, Michigan, USA: Holmes Group.

Iza, D. F. V., \& Souza Neto, S. (2015). Por uma revolução na prática de ensino - Estágio curricular supervisionado ( $1^{\mathrm{a}}$ ed.). Curitiba, Brasil: CRV.

Jolion, J-M (2011). La masterisation de la formation initiale des enseignants : Enjeux et bilan. Rapport remis au Ministre de l'Enseignement Supérieur et de la Recherche en octobre 2011. Recuperado de 
https://www.ladocumentationfrancaise.fr/ rapports-publics/114000624/index.shtml

Larson, M. S. (2014). Looking back and a little forward: Reflections on professionalism and teaching as a profession. Radical Teacher A Socialist, Feminist, and Antiracist Journal on the Theory and Practice of Teaching, 99, 7-17.

Lepage, M., Gervais, C., \& Malo, A. (2018, mai). Pour une concertation dans l'encadrement et laccompagnement des stagiaires en enseignement au Québec. Communication présenté dans le Colloque International du CRIFPE, Symposium 16, Montréal, Canada.

Libâneo, J.C., \& Pimenta,S. G. (1999). Formação de profissionais da educação: Visão crítica e perspectiva de mudança. Educação \& Sociedade, 20(68), 239-277. http://dx.doi. org/10.1590/S0101-73301999000300013

Marcelo, C. (1999). Formação de professores: Para uma mudança educativa. Porto: Porto Editora.

Maués, O. C. (2003). Reformas internacionais da educação e formação de professores. Cadernos de Pesquisa, 118, 89-118. http://dx.doi.org/10.1590/S010015742003000100005

MELS. (2004). La formation à l'enseignement, les stages. Québec, Canada: Gouvernement du Québec.

Nóvoa, A. (1987). Do mestre-escola ao professor primário: Subsídios para a história da profissão docente em Portugal (séculos XV - XX). Análise Psicológica, 3(V), 413440.

Nóvoa, A. (1992). Formação de professores e profissão docente. In A. Nóvoa (Org.), Os professores e a sua formação (pp. 13-33). Lisboa: Nova Enciclopédia.

Nóvoa, A. (1999). Os professores na virada do milênio: Do excesso dos discursos à pobreza das práticas. Educação e Pesquisa, 25(1), 11 20.
Nóvoa, A. (2011). O regresso dos professores. Pinhais: Editora Melo.

Nóvoa, A. (2012, junho). Pedagogia universitária: Já estamos no século XXI ou ainda não?. Conferência de abertura do VII Congresso Iberoamericano de Docência Universitária: Ensino Superior - Inovação e Qualidade na Docência, Faculdade de Psicologia e Ciências da Educação da Universidade do Porto, Porto, Portugal.

Nóvoa, A. (2017). Firmar a posição como professor, afirmar a profissão docente. Cadernos de Pesquisa, 47(166), 1106-1133. https://dx.doi.org/10.1590/198053144843

Sarti, F. M. (2012). O triângulo da formação docente: Seus jogadores e configurações. Educação e Pesquisa, 38(2), 323-338.

Sarti, F. M. (2013a). Pelos caminhos da universitarização: Reflexões a partir da masterização dos IUFM franceses. Educação em Revista, 29(4), 215-244. https://dx.doi. org/10.1590/S0102-46982013000400010

Sarti, F. M. (2013b). Relações intergeracionais e alternância na formação docente: Considerações a partir de uma proposta de estágio supervisionado. Cadernos de Educação, 46, 83-99. Recuperado de http:// periodicos.ufpel.edu.br/ojs2/index.php/ caduc/article/view/4174

Sarti, F. M., \& Araújo, S. R. P. M. (2016). Acolhimento no estágio supervisionado: Entre modelos e possibilidades para a formação docente. Educação, 39(2), 175-

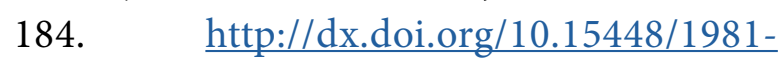
2582.2016.2.19415

Schön, D. (1992). Formar professores como profissionais reflexivos. In A. Nóvoa (Org.), Os professores e a sua formação (pp. 78-93). Lisboa: Dom Quixote.

Schön, D. (1993). Le praticien réflexif : $\grave{A}$ la recherche $d u$ savoir caché dans l'agir professionnel. Montréal: Les Éditions Logiques. 
Shulman, L. (1987). Knowledge and teaching: Foundations of the new reform. Harvard Educational Review, 57(1), 1-23. https://doi. org/10.17763/haer.57.1.j463w79r56455411

Silva, M. (2009). Complexidade da formação de profissionais: Saberes teóricos e saberes práticos. São Paulo: Cultura Acadêmica.

Souza, D. T. R. (2006). Formação continuada de professores e fracasso escolar: Problematizando o argumento da incompetência. Educação e Pesquisa, 32(3), 477-492. http://dx.doi.org/10.1590/S1517$\underline{97022006000300004}$

Souza, D. T. R., \& Sarti, F. M. (2014). Mercado de formação docente: Constituição, funcionamento e dispositivos. Belo Horizonte: Fino Traço.

Souza Neto, S., \& Benites, L. C. (2013). Os desafios da prática na formação inicial docente: Experiência da Educação Física da UNESP de Rio Claro. Cadernos de Educação, 46, 1-22. Recuperado de https://periodicos. ufpel.edu.br/ojs2/index.php/caduc/article/ view $/ 4170$

Souza Neto, S., \& Iaochite, R. (2015). O uso de dispositivos de acompanhamento de estágio curricular como elemento para se pensar a profissionalização do ensino. In E. M. L. Portilho \& A. M. D. P. Vieira (Orgs.), Anais do XII EDUCERE - Congresso Nacional de Educação (pp. 1-12). Curitiba, PR, Brasil: PUCPRess - Editora Universitária Champagnat.

Souza Neto, S., Sarti, F. M., \& Benites, L. C. (2016). Entre o ofício de aluno e o habitus de professor: Os desafios do estágio supervisionado no processo de iniciação à docência. Movimento, 22(1), 311-324. https://doi.org/10.22456/1982-8918.49700

Tardif, M. (2002). Saberes docentes e formação profissional. Petrópolis, RJ, Brasil: Editora Vozes.

Tardif, M. (2013). A profissionalização do ensino passados trinta anos: Dois passos para a frente, três para trás. Educação \& Sociedade, 34(123), 551-571. https://dx.doi. org/10.1590/S0101-73302013000200013

Tardif, M., Lessard, C., \& Gauthier, C.. (1998). Formation des maitres et contextes sociaux: Perspectives internationales (1re éd.). Paris: Presses Universitaires de France.

Vicentini, P. P., \& Lugli, R. G. (2009). História da profissão docente no Brasil: Representações em disputa. São Paulo: Cortez.

Villela, H. O. S. (2004). Do "saber fazer" a profissionalização docente na Escola Normal na Província do Rio de Janeiro. Revista Rio de Janeiro, 13-14, 49-67.

Zeichner, K. M. (2010). Repensando as conexões entre a formação na universidade e as experiências de campo na formação de professores em faculdades e universidades. Educação, 35(3), 479-504.

Zeichner, K. M. (2013). Políticas de formação de professores nos Estados Unidos: Como e porque elas afetam vários países do mundo. Belo Horizonte: Autêntica Editora.

\section{LEGISLAÇÃO CONSULTADA}

Lei $\mathrm{n}^{\circ} 11.788$, de 25 de setembro de 2008. Dispõe sobre o estágio de estudantes; altera a redação do art. 428 da Consolidação das Leis do Trabalho CLT. Diário Oficial [da] República Federativa do Brasil, Poder Executivo. Brasília, DF, Brasil. Recuperado de http://www.planalto.gov.br/ ccivil 03/ ato2007-2010/2008/lei/111788.htm

Lein ${ }^{\circ}$ 9.394, de 20 de dezembro de 1996. Estabelece as diretrizes e bases da educação nacional. Diário Oficial [da] República Federativa do Brasil, Poder Executivo. Brasília, DF, Brasil. Recuperado de http://www.planalto.gov.br/ ccivil 03/leis/19394.htm

Resolução $\mathrm{n}^{\circ} 1$, de 18 de fevereiro de 2002. Institui Diretrizes Curriculares Nacionais para a Formação de Professores da Educação 
Básica, em nível superior, curso de licenciatura, de graduação plena. Portal MEC. Brasília, DF: MEC/CNE/CP, 2002. Recuperado de: http://portal.mec.gov.br/ cne/arquivos/pdf/ rcp01 02.pdf. Acesso em: 20 out. 2014.

Resolução $\mathrm{n}^{\circ} 2$, de 1 de julho de 2015. Define as Diretrizes Curriculares Nacionais para a formação inicial em nível superior (cursos de licenciatura, cursos de formação pedagógica para graduados e cursos de segunda licenciatura) e para a formação continuada. Conselho Nacional de Educação. Brasília, DF, Brasil. Disponível em: http://portal.mec.gov. br/docman/agosto-2017-pdf/70431-res-cnecp-002-03072015-pdf/file

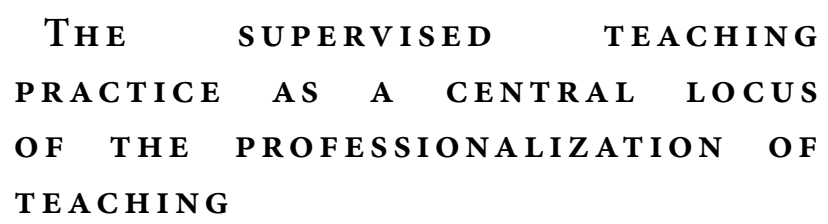

\section{Abstract}

This article brings some reflections about teacher education and the teaching professionalization movement, focusing on supervised teaching practice. There are two study questions to discuss: 1) How supervised teaching practice has been manifested in teacher education?; 2) Does the Brazilian and international reforms of initial teacher education take professionalization as a presupposition, namely in what concerns supervised teaching practice? Initially, we present the concept and some aspects of the teaching professionalization's process. Then, a brief trajectory about how teacher education practice is conceived and understood is presented. Subsequently, the text explores some concrete examples of Brazil, France and Canada. In the analyses, it is possible to identify that, with the professionalization process, the universities and higher education institutions take on teacher education, structuring and organizing themselves in order to respond to the requirements of teacher education, assuming elements of a professional model.

KeYworDs: Teacher education; Supervised teaching practice; Professionalization 
LE STAGE SUPERVISÉ COMME LIEU CENTRAL SUR LA PROFESSIONNALISATION D'ENSEI G N E MENT

\section{RÉSUMÉ}

Larticle porte sur la formation des enseignantes et sur le mouvement de professionnalisation d'enseignement, en particulier sur le stage supervisé. Il y a deux questions détude : 1) Comment la question de stage supervisé s'est manifestée dans la formation initiale des enseignants? ; 2) Les réformes proposées dans le cadre de la formation initiale des enseignants aux niveaux international et brésilien, en particulier dans le cadre du programme de stage, prennent-elles la professionnalisation comme présupposé? Initialement, se présentent le concept et quelques aspects sur le processus de la professionnalisation d'enseignement. Ensuite, est présentée une brève trajectoire à propos de la compréhension et conception de la formation pratique des enseignants. Subséquemment, sont explorés quelques exemples concrets du Brésil, de la France et du Canada. Dans les analyses réalisées, c'est possible d'identifier quà partir du processus de professionnalisation l'université et les institutions d'enseignement supérieur assument la formation des enseignants, se structurent et sorganisent pour répondre aux demandes spécifiques de la formation, en assumant des éléments de la propose du modèle professionnel de formation.

MotS-CLÉs : Formation des enseignants ; Stage supervisé ; Professionnalisation.

\footnotetext{
${ }^{\text {I }}$ Departamento de Educação, Instituto de Biociências, Universidade Estadual Paulista - Rio Claro, Brasil. ORCID: 0000-00028991-7039

"I Fundação Hermínio Ometto, Brasil. ORCID: 0000-0001-6286-8719

III Département de Psychopédagogie et Andragogie, Faculté d’Éducation, Université de Montréal, Canada.
} 